\title{
PREFERÊNCIA POR CESARIANAS EM GESTANTES NULÍPARAS DE UM CONSULTÓRIO PARTICULAR DE GINECOLOGIA E OBSTETRÍCIA: UM ESTUDO DE CASO
}

\author{
Ana Cláudia Farias NUNES ${ }^{1}$ \\ Déborah Karollyne Ribeiro RAMOS ${ }^{2}$ \\ Simone Karine da Costa MESQUITA ${ }^{3}$ \\ ${ }^{1}$ Enfermeira. Graduada pela Faculdade de Ciências Médicas de Campina Grande. E-mail: \\ claudia_fnunes@hotmail.com. \\ ${ }^{2}$ Enfermeira. Mestre em Enfermagem pela UFRN. Docente do Curso de Graduação em Enfermagem da FCM. Membro \\ do Grupo de Estudo e Pesquisa em Enfermagem - GEPE/FCM. E-mail: deborah.ribeiro.ramos@ gmail.com. \\ ${ }^{3}$ Enfermeira. Mestre em Enfermagem pela UFRN. Enfermeira da Estratégia de Saúde da Família do município de São \\ Gonçalo do Amarante-RN. E-mail: simone.karine@hotmail.com.
}

Recebido em: 30/05/2014 - Aprovado em: 22/09/2014 - Disponibilizado em: 15/12/2014

\section{Resumo}

A presente pesquisa teve como objetivo compreender os motivos pelos quais as gestantes nulíparas de um consultório particular de Ginecologia e Obstetrícia optaram pelo parto cirúrgico. Trata-se de um estudo de caso com abordagem qualitativa e enfoque exploratório-descritivo que foi realizado em um consultório particular de Ginecologia e Obstetrícia situado no município de Campina Grande/PB. Os sujeitos da pesquisa foram 12 gestantes, maiores de 18 anos, que nunca deram a luz. O período de coleta do material empírico foi em Outubro de 2013. O corpus originou-se de entrevistas semiestruturadas analisadas por meio da técnica de análise de conteúdo temática. Os resultados foram agrupados em quatro categorias, a saber: Categoria 1 - Influência de histórias contadas por familiares ou terceiros; Categoria 2 - A influência da mídia e a opção pelo parto cesáreo; Categoria 3 - Medo do sofrimento que envolve o trabalho de parto; Categoria 4 - Pato cesáreo como reflexo do status social. De modo geral as participantes do estudo mostraram que a discussão que culmina na decisão pelo parto cirúrgico, reflete um processo cognitivo que envolve não apenas aspectos médicos, mais também fatores socioeconômicos, culturais e pessoais. Acreditamos ser premente uma análise da qualidade das informações passadas às gestantes durante o pré-natal, a fim de que possamos detectar as prováveis falhas desse processo educativo e trabalharmos na perspectiva de transformação da prática da educação junto as gestantes para o parto.
\end{abstract}

Palavras-chave: Saúde da mulher. Parto cirúrgico. Cesárea. Parto obstétrico. Preferência do paciente.

\section{Introdução}

O parto cirúrgico ou cesáreo é indicado como uma alternativa para interrupção da gravidez quando esta não evolui normalmente e surgem agravos que possam colocar a vida da mãe e/ou do filho em risco. De acordo com a Organização Mundial de Saúde, considera-se aceitável um índice de 10 a $15 \%$ de cesarianas e $85 \%$ para partos vaginais, expectativas estas que não correspondem à nossa realidade. Atualmente, cerca de $35 \%$ dos partos realizados no país são cesarianas e ao levarmos em consideração apenas o serviço privado, esta estimativa chega a ser de 70\% (MANDARINO et al., 2009).

Segundo Freitas et al. (2005), no Brasil o índice de cesarianas é maior em mulheres com melhor poder aquisitivo, de etnia branca e em hospitais particulares, ou seja, em mulheres com menor potencial para riscos obstétricos. A aplicação indiscriminada da cesariana reflete uma nova realidade na qual o parto passa a ser um evento programado, determinado na maioria das vezes apenas pelo desejo da mãe, ignorando 
suas reais aplicações clínicas e suas possíveis complicações - já que é considerada uma cirurgia abdominal de grande porte.

A gestação é um evento especial na vida da mulher e muitas vezes a sensação de ser mãe é permeada por incertezas e inseguranças. As transformações vividas no período gestacional são novidades, principalmente para as gestantes nulíparas, e dúvidas relacionadas aos tipos de partos geralmente tornam-se um dilema. Com a evolução da gravidez a termo, o medo do desconhecido associado à falta de informação correta muitas vezes precipita a escolha por um parto cirúrgico.

Dentro desse enfoque, estudos mostram que a "epidemia de cesarianas" corrobora de forma direta com as mudanças apresentadas pelos dados estatísticos do nosso país, interferindo no processo de adesão ao parto normal por gestantes nulíparas e na corrente pré-estabelecida do conceito de "que uma vez cesáreo, sempre cesáreo", representando assim um problema de saúde pública. É importante reforçar que uma cesariana para ser bem realizada e indicada, precisa da confirmação de precedentes necessários e que complicações inerentes a qualquer procedimento cirúrgico não estão descartadas (CARDOSO; BARBOSA, 2012; FREITAS et al, 2005; MANDARINO et al., 2009; SOUSA, 2002).

Diante do que foi exposto, nos interessou responder com o presente estudo, ao seguinte questionamento: "Por que grande parte das gestantes nulíparas opta pelo parto cesáreo?".

Este estudo justifica-se pela necessidade de um enfoque maior sobre as questões que envolvem cesarianas em gestantes nulíparas, já que o próprio Ministério da Saúde (BRASIL, 2001) preconiza a realização do parto vaginal sempre que possível, como sendo a via de parto mais segura para mãe e filho.

Ressaltamos que ao desconsiderarem as situações clínicas indicativas para uma cesariana, as mães se submetem a riscos desnecessários, além de acarretar em uma recuperação mais lenta e de elevar os gastos com internações hospitalares e medicamentos, condições que não estão presentes quando acontece o nascimento do feto por via vaginal.

O presente estudo tem como objetivo identificar os motivos pelos quais as gestantes nulíparas de um consultório particular de Ginecologia e Obstetrícia de Campina Grande, optaram pelo parto cirúrgico.

Acreditamos que identificar as principais razões que levam as nulíparas a optarem pelo parto cesariano pode contribuir para a reversão dessas correntes adversas às recomendações do Ministério da Saúde que preconiza a via de parto vaginal como sendo a mais segura e benéfica para mãe e filho.

\section{Método}

Trata-se de um estudo de caso com abordagem qualitativa e enfoque exploratório- 
descritivo, desenvolvido em um consultório particular de Ginecologia e Obstetrícia, localizado no município de Campina Grande, PB. Atualmente, o consultório cenário da pesquisa realiza uma média de 200 atendimentos mensais. Dos quais, 30\% destes são atendimentos ginecológicos e 70\% assistência obstétrica. Dos atendimentos obstétricos, cerca de $20 \%$ em média são de gestantes nulíparas.

Optou-se pelo consultório particular como lócus da pesquisa por acreditarmos que é nesse cenário que a mulher tem autonomia para escolher a via de parto que prefere. Tendo em vista que o Ministério da saúde (BRASIL, 2001) preconiza o parto normal como sendo a via mais saudável e segura para mãe e filho e que a cesariana é indicada apenas quando respaldada por fundamentos clínicos, acreditamos que tal fato poderia induzir/camuflar/alterar resultados caso esta pesquisa fosse realizada em um serviço do Sistema Único de Saúde.

Os sujeitos da pesquisa foram 12 mulheres gestantes, nulíparas, que optaram pela via de parto cirúrgico e que frequentam regularmente e realizam o pré-natal no consultório selecionado como cenário da pesquisa, no período de coleta do material empírico que aconteceu no mês de Outubro de 2013.

Foram incluídas na pesquisa mulheres maiores de 18 anos, nulíparas, que estivessem realizando pré-natal no consultório lócus do estudo e que, para o nascimento do filho que estão gestando, optaram pela via de parto cesáreo.

Para a coleta do material empírico utilizamos a entrevista semi-estruturada. O material empírico foi analisado através da técnica de análise temática proposta por Minayo (2000). Para tanto, os procedimentos pós-entrevista adotados foram: 1) transcrição na íntegra das gravações; 2) leitura e conferência do material; 3) envio do texto ao depoente para correção; 4) análise temática.

Para operacionalização da pesquisa, o projeto foi submetido à apreciação do Comitê de Ética em Pesquisa do Centro de Ensino Superior e Desenvolvimento - CESED, recebendo aprovação dessa instância sob CAAE de número 21355413.0.0000.5175.

\section{Resultados e discussão}

De forma geral, observamos que as gestantes entrevistadas estão na faixa etária entre 26 e 29 anos, são casadas, com nível de escolaridade predominantemente superior completo/incompleto e renda média entre 1 e 3 salários mínimos.

Os resultados encontrados durante a realização das entrevistas foram agrupados em 4 categorias de análise: Influência de histórias contadas por familiares ou terceiros; A influência da mídia e a opção pelo parto cesáreo; Medo do sofrimento que envolve o trabalho de parto; Pato cesáreo como reflexo do status social. 


\section{Categoria I - Influência de histórias} contadas por familiares ou terceiros

De acordo com os discursos dos sujeitos desta pesquisa um dos fatores mais importantes relacionados à escolha das gestantes pelo parto cesáreo é a forte influência que relatos de familiares e de pessoas próximas exercem sobre essa escolha.

Vejamos os recortes que se seguem:

“Minha irmã teve bebê há pouco tempo... Ela disse que foi horrível, que não era pra ela ter tido normal não, que era pra ter sido cesáreo, mas o médico deixou ela sofrendo lá até a menina nascer”. [Entrevistada 2]

"Sim, minha cunhada mesmo, porque o outro filho dela ela sofreu muito quando foi ter $e$ ela já tinha me aconselhado a ter cesáreo, cortaram ela demais no normal sabe?". [Entrevistada ]

"Já ouvi demais que o parto normal dói muito, que o médico corta a mulher, afff Maria, machuca demais... É, a gente escuta as mulheres dizerem que dói demais e que a história de ficar lá esperando a dilatação é triste... Quero isso nada”. [Entrevistada 2]

Pesquisadores como Bezerra e Cardoso (2006), já dimensionaram em um estudo anterior que a influência da família e da sociedade sobre os sentimentos da mulher a respeito do parto, interfere na decisão dessas gestantes. Tais autores ainda reforçam a ideia de que a família e os laços de amizades desenvolvidos refletem sobre a formação que a mulher tem acerca da gestação e o parto.

$\mathrm{O}$ relato de experiências traumáticas parece ser um fator determinante para escolha da cesariana. Oliveira et al. (2002) reforça esta hipótese ao afirmarem que as gestantes ao serem confrontadas com relatos e informações passada por terceiros sobre o trabalho de parto normal podem ser influenciadas de forma negativa ou positiva, dependendo da interpretação individual de cada uma.

Neste contexto, as falas das gestantes expressam que a decisão não foi pautada na indicação médica ou aplicação de cada tipo de parto e sim que teve como base a experiência negativa retratada por familiares e/ou amigos.

Nota-se também, que o medo da gestante com relação à assistência que poderá receber no serviço público, devido a experiências traumáticas vividas por terceiros durante o parto, pode interferir numa decisão por um parto cesáreo e uma assistência privada. Tais achados podem ser associados a um estudo realizado por Hotimsky et al. (2002) que também retrataram a vivência acima citada.

Sabemos que as transformações vividas no período gestacional são novidades, principalmente nas gestantes nulíparas, e dúvidas relacionadas aos tipos de partos geralmente tornam-se um dilema. Com a evolução da gravidez a termo, o medo do desconhecido associado à falta de informação 
correta, muitas vezes precipita a escolha por um parto cirúrgico.

Desse modo, acreditamos que existe a interferência das histórias contadas pelos familiares e amigos na escolha dessas gestantes pelo parto cirúrgico e que se torna imprescindível que uma informação correta seja transmitida a essas gestantes no preparo para o parto, a fim de reverter essa corrente crescente de cesarianas eletivas.

Uma alternativa para minimizar a influência negativa das histórias contadas por terceiros e pela própria mídia seria a educação em saúde. Para Martins (2006) a educação em saúde representa uma prática social, um processo sistemático e contínuo, com conteúdo científico, técnico, político e pedagógico, que contribui para a formação e desenvolvimento da consciência crítica das pessoas visando à participação da população na busca de qualidade de vida, como sujeito ativo e transformador da realidade.

No contexto da educação em saúde, a Enfermagem assume papel interdisciplinar no processo educativo. Considera-se que tal processo constitui um instrumento para a promoção não apenas da saúde, mas da qualidade de vida dos indivíduos. Essa nova forma de prática se insere no contexto da Enfermagem como um elo para o estabelecimento de um desenvolvimento dialógico-reflexivo acerca das novas características das formas de nascimento do nosso país, com o propósito de intervir de forma conscientizadora e não impositora, a fim de reverter tal realidade (SOUSA et al., 2010).

\section{Categoria II - A influência da mídia e a opção pelo parto cesáreo}

A busca por informações na mídia aberta representa um aspecto que colabora com a tomada de decisão da gestante, como anteriormente citado. Sites que disponibilizam a visualização de vídeos acerca dos tipos de parto provavelmente são uma das principais fontes de busca por informações procuradas por essas mulheres.

Atentemos ao relato a seguir:

"Isso foi uma coisa que a gente [gestante e companheiro] conversou muito, pesquisamos vídeos no YouTube sobre o parto normal $e$ cesariana... Assim, eu não queria sentir a dor do parto, no começo ele [companheiro] ainda assistiu comigo, porque ouvia dizer que o normal é melhor... [risos]Mas assim, depois que ele viu os vídeos sabe, disse que era melhor mesmo ter cesáreo, porque ele quer filmar e é até mais bonito [risos]". [Entrevistada 6]

“Assisti no jornal, sei lá, essas coisas que a gente vê que bebê morreu na barriga da mãe porque passou da hora do menino nascer, essas coisas". [Entrevistada 4]

Notamos uma nítida discussão entre a participante e o companheiro, que de certa forma tentou reverter o pensamento da gestante, exaltando os benefícios do parto normal. Entretanto, após a visualização de 
vídeos sobre os tipos de parto foi $o$ companheiro quem ficou convencido que a melhor opção seria o parto cirúrgico. Outro ponto que nos chama atenção é a opção pela cesariana simplesmente porque ficaria "mais bonito" para a filmagem, mostrando uma nova realidade: a estética do nascimento participando como um fator determinante para a escolha do tipo de parto.

Grande parte das gestantes se impressiona com a visão do parto normal em pesquisas na internet e reportagens de eventos traumáticos relacionados ao trabalho de parto natural, fato que também interfere na percepção pessoal das futuras mães como veremos a seguir:

“No começo eu pensava em ter normal, mas depois que eu vim de Recife morar aqui eu já ouvi muita história e mais pra mim que a família tá longe... Já ouvi muita história ruim mesmo, não tenho medo da dor nem nada, mas é do procedimento... já vi alguns partos normais na internet e vi muitas mulheres sendo rasgadas, aí decidi ter cesáreo, o normal é muito feio de se ver". [Entrevistada 8]

Em consonância com trabalho publicado por Oliveira et al. (2002), acreditamos que as expectativas das gestantes quanto ao trabalho de parto estão associadas a forma com que as informações lhe são transmitidas ou como elas procuram receber e interpretar essas informações.
De tal modo, ao fim da análise dos recortes de falas agrupadas nesta subcategoria inferimos que as informações adquiridas durante a gestação, sejam elas de fontes seguras ou não, tendem a interferir e até mesmo a direcionar as gestantes na escolha da via de parto (in) adequada. Por este motivo, acreditamos ser fundamental o trabalho do profissional de saúde junto a gestante, para que sejam esclarecidas dúvidas, para que procedimentos técnicos, visualizados em vídeos e reportagens, sejam desmistificados, enfim para construir um saber coletivo (entre profissional da saúde e gestante) acerca da via de parto que melhor se adéqua às necessidades da mulher.

\section{Categoria III - Medo do sofrimento que envolve o trabalho de parto}

Dor, sofrimento, violência Obstétrica no momento da Episiotomia e medo de algo sair errado foram relatados durante as entrevistas, ao indagarmos o principal motivo que as levaram a escolher o parto cirúrgico. Vejamos os recortes que se seguem:

"Porque eu acho que ter filho normal deve doer demais, aí sempre quis cesariana quando engravidasse... Aí pronto!". [Entrevistada 1]

“Ahhh... Sei lá, eu só acho que o parto normal deve ser ruim, doer muito. E também queria programar, me organizar [risos] $e$ também tem uma coisa que eu acho meio estranha, porque não sei se a mulher fica 
deformada depois que tem filho normal...". [Entrevistada 5]

"Porque eu acho mais seguro e menos traumático pra mãe, por que o normal não é muito bonito de se ver, imagina viver". [Entrevistada 11]

O parto normal é retratado como um processo árduo, com a dor maior que o esperado. As mulheres expressam o temor da dor intensificado pelas histórias ouvidas, acrescidas de procedimentos dolorosos e inesperados, como a realização da episiotomia, que na percepção das gestantes representa uma agressão à integridade da genitália feminina (SILVA; LOPES; DINIZ, 2002).

Oliveira et al. (2002) reforçam esses achados ao descreverem que o desejo pela cesárea é determinado pelo receio de sentir dores e a possibilidade de acontecer complicações durante o parto normal que podem colocar a vida do recém nascido ou da mãe em risco.

Ainda devemos salientar que Neme (2000) retrata que a intensidade da dor do parto é amplamente variável e está sujeita a interferências psíquicas, comportamentais e culturais. Dessa forma, podemos correlacionar os achados desta subcategoria com os achados da Categoria II, os quais refletem a influência de fatores externos na escolha da gestante acerca da via de parto.

Como citado anteriormente, a maioria das mulheres que procuram uma assistência
Obstétrica particular, buscam vivenciar uma experiência positiva da gestação. Ao se analisar as respostas dos sujeitos da pesquisa, pode-se observar que a maioria destas planejaram a gestação (das 12 entrevistadas apenas 4 disseram não ter planejado a gravidez), o que aponta para outro aspecto interessante:o parto passou a ser um acontecimento institucionalizado, programado, deixando de ser um processo natural e inerente a fisiologia feminina.

A participação feminina no parto segue preceitos históricos e culturais. Eventos como menstruação, gravidez e o processo de parturição eram restritos às mulheres, geralmente auxiliados pelas mais velhas da família, vizinhas ou comadres que ao longo dos anos foram adquirindo prática $\mathrm{e}$ repassando para as gerações futuras. Eram mulheres de confiança, que as assistiam em suas casas, auxiliando nos partos e em outros aspectos relacionados à saúde da mulher (BARROS, 2002).

Desse modo, ao serem indagadas sobre a escolha da cesariana em detrimento do parto normal, grande parte das entrevistadas já adentraram ao consultório médico com uma concepção irrefutável acerca da positividade da cesariana, independentemente dos benefícios demonstrados no consultório sobre o parto normal. 


\section{Categoria IV - Pato cesáreo como reflexo} do status social

Nossas interpretações sobre as respostas das gestantes nos possibilitaram inferir que, para os sujeitos deste estudo, a escolha por uma cesariana representa o reflexo de seu status social, como veremos no trecho a seguir:

"Acho que a empregada daqui teve todos três filhos normais... Assim, se posso pagar pra ter uma coisa mais segura, certa, por que não? Acho que o normal é mais no SUS”. [Entrevistada 6].

“Esperei pra engravidar quando tivesse trabalhando e pudesse pagar um plano de saúde, pra poder ter uma gravidez mais tranquila, a gente escuta cada coisa no SUS...”[Entrevistada 12]

"Minha mãe disse que eu não precisava sofrer como ela sofreu no SUS, que eu tinha dinheiro e podia pagar, por isso também quis a cesárea, que é só marcar e pronto, não preciso sofrer". [Entrevistada 12].

A indústria de cesarianas no nosso país reflete uma nova realidade da sociedade brasileira: a ascensão social, como reflexo do status econômico. Tal realidade é amplamente difundida em grande parte dos consultórios particulares do nosso país, lócus este que representa o espaço onde a autonomia feminina é respeitada, já que o parto normal é priorizado na estratégia abordada pelo
Ministério da Saúde que preconiza o parto normal como sendo a primeira opção (BRASIL, 2001).

Aspecto importante é abordado por Amorim, Souza e Porto (2010) ao comentar a busca pelo "Obstetra ideal", representado por aquele que aceita a demanda de cesarianas eletivas, provavelmente pelo retorno financeiro de tal procedimento, ao invés de respeitar os aspectos clínicos da indicação da cesariana com respaldo científico.

Deste modo fica nítida a associação de fatores socioeconômicos com a escolha da via de parto, principalmente ao considerarmos que quanto maior o nível econômico, maior o poder de escolha quanto ao tipo de parto e consequentemente o poder de decisão da mulher.

Apesar dos sujeitos da pesquisa não terem apresentando conhecimento científico sobre os procedimentos técnicos realizados durante o parto cesáreo, ficou nítida a indiferença que estes exercem na escolha das gestantes.

\section{Conclusão}

A partir da análise das falas dos sujeitos concluímos de maneira geral, que uma série de fatores podem influenciar a escolha dessas gestantes pela via de parto cesáreo, a saber: o medo da dor e violência obstétrica idealizadas com o nascimento por via vaginal; a interferência do discurso de familiares e terceiros sobre experiências de parturição; a interpretação das informações 
adquiridas em consultórios ou em outras fontes de informação e a interferência dos fatores socioeconômicos como sendo determinantes para a escolha do tipo de parto.

Observamos que a maioria das gestantes entrevistadas planejaram a gestação e consequentemente escolheram a cesárea como sendo a via de parto mais segura para o nascimento do seu filho. Algumas referiram procurar informações acerca da positividade da cesariana em detrimento ao parto normal, antes mesmo de engravidarem.

Outro aspecto importante relacionado à preferência das gestantes pelo parto cesáreo é a influência que a família e pessoas inseridas no contexto social da gestante, exerce nessa escolha. A preferência pela via de parto é ressaltada aqui, segundo experiências, relatos e convicções desses indivíduos influentes.

No tocante a influência da mídia de livre acesso, concluímos que a falta de controle na divulgação dessas informações associada à disponibilidade destas, também interfere na percepção de cada gestante sobre a perspectiva de parto. Vale salientar que grande parte das gestantes já procura o consultório particular com o intuito de agendar uma cesariana.

Para que as mulheres possam escolher adequadamente o melhor tipo de parto, segundo sua condição de saúde, crenças e valores pessoais, é fundamental que elas se sintam completamente informadas.
Acreditamos ser premente uma análise da qualidade das informações passadas às gestantes durante o pré-natal, a fim de que possamos detectar as prováveis falhas desse processo educativo e trabalharmos na perspectiva de transformação da prática da educação junto às gestantes, para que assim elas optem pela via de parto de maneira mais segura, diminuindo a ansiedade e a insegurança, preparando-as, de fato, para o parto.

\section{Referências}

AMORIM, M. M. R.; SOUZA, A. S. R.; PORTO, A. M. F. Condições frequentemente associadas com cesariana, sem respaldo científico: resumo. Femina. v. 38; n. 10. P. 505-516. Setembro de 2010. Disponível em: <http://files.bvs.br/upload/S/01007254/2010/v38n10/a1708.pdf>

Acesso: 30 mai. 2014.

BARROS, F. B. M. (org) A formação do fisioterapeuta na saúde da população: atuação transformadora. Rio de Janeiro: FisioBrasil, 2002.

BEZERRA, M. G. A.; CARDOSO, M. V. L. M. L. Fatores culturais que interferem nas experiências das mulheres durante o trabalho de parto e parto. Revista latino americana de enfermagem, Ribeirão Preto, v. 14, n. 3, 2006. Disponível em: 
$<$ http://www.scielo.br/pdf/rlae/v14n3/v14n3a

16.pdf $>$.

Acesso em: 30 mai. 2014.

BRASIL. Ministério da Saúde. Secretaria de Política de Saúde. Área técnica de Saúde da

Mulher. Parto, aborto e puerpério:

assistência humanizada à mulher. Brasília:

Ministério da Saúde, 2001.

CARDOSO, J. E.; BARBOSA, R. H. S. O

desencontro entre desejo e realidade: a" indústria" da cesariana entre mulheres de camada média do Rio de Janeiro, Brasil.

Physys: Revista de Saúde Coletiva. v. 22; n.1;

p. 35-52. Jan. 2012. Disponível em $<<$

http://www.scielo.br/pdf/physis/v22n1/v22n1

a03.pdf $>>$

Acesso: 30 mai 2014.

FREITAS, P. F. et al. Desigualdade social nas taxas de cesarianas em primíparas do Rio

Grande do Sul. Revista de Saúde Pública. v.39; n. 5; p. 761-767. 2005. Disponível em < http://www.scielosp.org/pdf/rsp/v39n5/26296. pdf >

Acesso: 30 mai. 2014.

HOTIMSKY, S. N. et al. O parto como eu vejo... ou como eu o desejo? Expectativas de gestantes, usuárias do SUS, acerca do parto e da assistência obstétrica. Caderno de saúde pública, Rio de Janeiro, v. 18, n. 5, 2002.

Disponível em: < http://www.scielo.br/pdf/csp/v18n5/11003.pdf $>$.

Acesso em: 30 mai. 2014.

\section{MANDARINO, N. R. et. al. Aspectos} relacionados à escolha do tipo de parto: um estudo comparativo entre uma maternidade pública e outra privada, em São Luís, Maranhão, Brasil. Cadernos de Saúde

Pública. v. 25; n. 7; p. 1587-1596. Disponível em $<<$

http://www.scielo.br/pdf/csp/v25n7/17.pdf $>>$ Acesso: 30 mai. 2014.

MARTINS, Josiane de Jesus et. al.

Necessidades de educação em saúde dos cuidadores de pessoas idosas no domicílio.

Florianópolis, Abril -Junho, 2007. Disponível no site:

<http://www.scielo.br/pdf/tce/v16n2/a07v16n 2.pdf $>$.

Acesso: 30 mai. 2014.

NEME, B. Obstetrícia básica. São Paulo: Sarvier, 2000.

OLIVEIRA, S. M. J. V. et al. Tipo de pato: expectativas das mulheres. Revista latino Americana de Enfermagem, Ribeirão Preto, v. 10, n. 3, 2002. Disponível em: <http://www.scielo.br/pdf/rlae/v10n5/v10n5a 7.pdf>.

Acesso em: 30 mai. 2014. 
SILVA, J. M.O.; LOPES, R. L. M.; DINIZ,

N. M. F. Uma aproximação ao ser adolescente

prímipara através as entrevista

fenomenológica. Rev.. Enfermagem. UERJ.

2002. Set-dez; p. 222-225.

SOUZA, M. R. Parto: entre o desejo e a

realização. In: XIII Encontro da Associação

Brasileira de Estudos Populacionais. Belo

Horizonte: Minas Gerais, 2002. 